\title{
Rede de atenção aos usuários de substâncias psicoativas: mapeamento de serviços e equipes de enfermagem ${ }^{1}$
}

\section{Network of attention of the user of psychoative substances: search of the services and nursing staff}

\section{Red de atención al usuario de substancia psicoativas: examen de servicio y conjunto de enfermaria}

\author{
Bruna Trindade Ambrósio', Fernanda Bissoli Benincá", Maykel Marques Fejoli"l, \\ Marluce Miguel de Siqueiralv, Vitor Buaiz ${ }^{\mathrm{V}}$
}

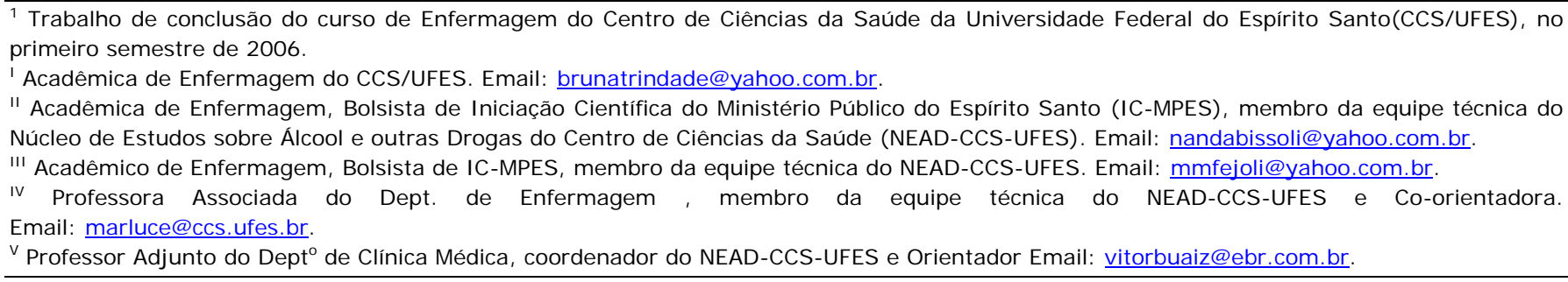

\section{RESUMO}

O uso de substâncias psicoativas no Brasil se constitui em um problema de saúde pública e, no Espírito Santo, a política de atenção ao dependente químico vem se modificando nas últimas décadas. O estudo objetivou mapear serviços e equipes de enfermagem de todas as instituições que desenvolvem ações de caráter preventivo e/ou curativo no Espírito Santo, nos anos de janeiro de 2004 a dezembro de 2005. Trata-se de estudo exploratório quali-quantitativo. Partiu-se da listagem do 1ㅇ levantamento estadual e através da técnica da bola de neve acrescidas novas instituições. Verificou-se que 59,4\% encontram-se na macrorregião centro. Os GAMs representam $61,8 \%$ da oferta de tratamento nesta região e o tratamento ambulatorial $(68,5 \%)$ é superior a internação $(61,8 \%)$. A droga mais prevalente é o álcool $(68,4 \%)$ e a maior concentração de instituições com equipe de enfermagem, situa-se na macrorregião centro e $80 \%$ das instituições não-governamentais não apresentam enfermagem na equipe. Conclui-se que existe escassez de serviços governamentais disponíveis para atendimento desta população, bem como déficit de recursos humanos da enfermagem, o que reflete baixa qualidade no atendimento prestado. Portanto, é necessário a implementação de políticas para acelerar a municipalização das ações bem como fixar recursos humanos qualificados nesta área.

Descritores: Transtornos Relacionados ao Uso de Substâncias; Saúde Pública; Enfermagem Psiquiátrica.

\section{ABSTRACT}

This paper aims at accomplishing a search of specialized institutions in treatment in users of psychoactive substances and also a search of nursing staffs in Espírito Santo. The study involved restore and preventive institutions of 78 municipalities. The study started off from the first compilation in the state and through the snowball technique new institutions were added. In the data collection a semi-structured instrument was used containing data about the staff and the treatment. Quantitative and qualitative methods were used in the analysis. Most institutions are in the central macro region (59,4\%). The GAMs represent $61,8 \%$ of the treatment in that region and the outpatient clinic treatment $(68,5 \%)$ outnumbers internment $(61,8 \%)$. The prevailing drug is alcohol $(68,4 \%)$ and the biggest concentration of institutions that have nursing staff is located in the central micro region and $80 \%$ of the non-government institutions did not have nursing in their staffs. There is a lack of government services to assist such population, as well as a deficit of human resources mainly as of nursing, which reflect the low quality service offered. Therefore, it is necessary the implementation of policies to speed actions as well as to settle down qualified human resources in this field.

Descriptors: Substance-Related Disorders; Public Health; Psychiatric Nursing.

\section{RESUMEN}

En lo Espírito Santo, la política del atencion al dependente químico esta se modificando en las últimas décadas. El trabajo realizou examen de servicios de las instituiciones de carácter preventivo y curativo en el tratamiento de usuarios de substancias psicoactivas y equipos de enfermería del Espírito Santo en los años de enero de 2004 a diciembre de 2005 . A partir de la lista de 1 a investigación Estadual fueron agregadas nuevas utilizando la técnica de la bola de nieve. En la análisis fue usado los metodos cuantitativo y cualitativo. $59,4 \%$ de las instituiciones son de la macroregión centro. Los GAMs representan $61,8 \%$ de la oferta de tratamiento en esa región y el cuidado ambulatorial $(68,5 \%)$ es superior a la internación $(61,8 \%)$. La droga predominante es el alcohol $(68,4 \%)$ y la concentración de instituiciones con equipos de enfermería están en la macroregión centro. $80 \%$ de las instituiciones no gobernamentales no ofrecen enfermería en el equipo. Por lo tanto existe escasez de servicios gobernamentales para atendimiento de esta población, déficit de recursos humanos de la enfermería, lo que refleja baja cualidad en el atendimiento siendo necesario la implementación de políticas para acelerar las acciones y mantener recursos humanos cualificados en esta area.

Descriptores: Trastornos relacionados con sustancias; Salud Pública; Enfermería Psiquiátrica. 


\section{NTRODUÇÃO}

O consumo de substâncias psicoativas é um fenômeno civilizatório, ou seja, sempre existiu em todas as culturas humanas o uso de substâncias que alteram 0 estado de consciência. Porém, as características desse consumo, vêm se modificando significativamente nas últimas décadas, colocando em risco a vida de muitas pessoas, tornando-se mais um dos fatores estressantes, reflexo das transformações nas condições sociais e culturais decorrentes do incremento da crise econômica do país, com o conseqüente desemprego estrutural e o aumento da criminalidade ${ }^{(1)}$.

Tal modificação vem acarretando o desenvolvimento da síndrome de dependência que, segundo a Organização Mundial da Saúde (OMS), se caracteriza por "um conjunto de fenômenos fisiológicos, comportamentais e cognitivos em que o uso de uma substância alcança uma prioridade muito maior para o indivíduo que outros comportamentos que antes tinham maior valor". A síndrome de dependência de drogas é considerada doença crônica e, como tal, acompanha o indivíduo por toda sua vida; traz repercussões graves e o número de pessoas que sofre direta ou indiretamente com essa problemática é bastante expressivo. Segundo o estudo de Carter e Mcgoldrick, para cada caso de alcoolismo, mais quatro a cinco pessoas são afetadas direta ou indiretamente com as conseqüências físicas, psíquicas e sociais decorrentes desta doença ${ }^{(2-4)}$.

O uso indevido de substâncias psicoativas constitui-se, na atualidade, em grave problema de saúde pública e vem requerendo ações, tanto de repressão à oferta, quanto de redução da demanda. Suas conseqüências acarretam consideráveis prejuízos às nações do mundo inteiro e não são detidas por fronteiras: avançam por todos os cantos da sociedade, afetando homens e mulheres de diferentes grupos étnicos, independentemente de classe social e econômica ou mesmo de idade ${ }^{(5)}$.

Os custos da dependência incluem gastos pessoais e familiares, do sistema de saúde, de perdas laborais, de redução de impostos, do sistema judicial e correcional, de serviços policiais, exercendo um peso importante no orçamento nacional ${ }^{(5)}$.

Somente $23 \%$ dos dependentes de drogas procuram serviços de tratamento específico para a problemática, sendo que muitos não os procuram por falta de recursos financeiros. As pessoas de classes menos abastadas são as que mais sofrem quando envolvidas nessa situação, em função da insuficiência de serviços públicos de atenção à dependência de álcool e outras drogas ${ }^{(1)}$.

O sistema de saúde do país vem sofrendo constantes mudanças desde o século passado, acompanhando as transformações econômicas, socioculturais e políticas da sociedade brasileira ${ }^{(6)}$.
O relatório final da $8^{a}$ Conferência Nacional de Saúde de 1986 serviu de base para a elaboração do capítulo sobre saúde da Constituição Federal de 1988 que, incorporando parcialmente as propostas estabelecidas pelo movimento de reforma sanitária brasileira, criou o SUS, o qual foi regulamentado pelas Leis 8.080 , de 19 de setembro de 1990 e 8.142 , de 28 de dezembro de 1990. Na Constituição temos que "A saúde é um direito de todos e dever do Estado", ou seja, todo indivíduo tem garantido o acesso às ações de prevenção, promoção e recuperação da saúde. E o governo deve garantir este acesso, através da formação de uma rede de serviços de saúde e da execução de ações de saúde ${ }^{(6)}$.

A Constituição também legitima o direito universal, sem qualquer discriminação, ao acesso às ações de saúde em todos os níveis de complexidade, assim como explicita que o dever de promover o pleno usufruto deste direito, é do Estado. Por último, a Constituição estabelece o caráter público do SUS, formado por uma rede regionalizada, hierarquizada e descentralizada com direção única em cada esfera de governo, e sob controle da sociedade, em que os serviços privados, conveniados e contratados passam a ser complementares e subordinados às diretrizes do SUS ${ }^{(7)}$.

Ainda na década de 1980, com a realização da VIII Conferência Nacional de Saúde, observa-se uma progressiva mudança no enfoque da atenção em saúde mental, na qual ocorre uma transferência de ênfase nas internações para os serviços de atenção primária e secundária. Neste período é de especial importância o surgimento do primeiro Centro de Atenção Psicossocial (CAPS) do Brasil na cidade de São Paulo em 1987. Em 1989 dá entrada no Congresso Nacional o Projeto de Lei do deputado Paulo Delgado (PT MG), que propõe a regulamentação dos direitos das pessoas com transtornos mentais e extinção progressiva dos manicômios no país ${ }^{(8)}$

$\mathrm{Na}$ década de 1990, marcada pelo compromisso firmado pelo Brasil na assinatura da Declaração de Caracas, estabeleceu-se que a atenção psiquiátrica passa a ser colocada em estreita vinculação com a atenção primária, deixando o hospital psiquiátrico de ser o componente central ${ }^{(9)}$.

Após várias portarias o Ministério da Saúde (MS) promulga a Política de Atenção Integral aos Usuários de Álcool e outras Drogas (PAIUAD). As diretrizes da PAIUAD são: intersetorialidade e atenção integral. Esta, por sua vez, subdivide-se em: prevenção, promoção e proteção à saúde de consumidores de álcool e outras drogas; modelos de atenção (CAPS e Redes Assistenciais) e controle de entorpecentes e substâncias que produzem dependência física ou psíquica, e de precursores ${ }^{(10)}$. 
Também nos anos 90, mais precisamente, em novembro de 1998, durante o I Fórum Nacional Antidrogas ocorrido em Brasília, começaram a ser coletadas as primeiras contribuições da sociedade para aquilo que viria a ser a Política Nacional AntiDrogas (PNAD), que, somente no II Fórum Nacional Anti-drogas, ocorreu a sua homologação.

A PNAD (2001) foi elaborada pela Secretaria Nacional Anti-drogas (SENAD), o Departamento da Polícia Federal (DPF) e os outros agentes do Sistema Nacional Anti-drogas (SISNAD), com objetivos e diretrizes bem definidos para redução da oferta e da demanda de drogas vinculados à prevenção, tratamento, recuperação, reinserção social, redução de danos, repressão, estudos, pesquisas e avaliações $^{(11)}$.

Em 17 de fevereiro de 2003, a Presidência da República determinou a integração das Políticas Públicas com a PNAD e em março de 2003, houve um seminário de governo intitulado "Novos Cenários para a PNAD", ao qual compareceram todos os órgãos da República, em nível de ministério, que trouxeram suas contribuições para essa integração. Na oportunidade, foi assinado um Protocolo Coletivo de Intenções para ações conjuntas na PNAD entre onze ministérios do Governo Federal ${ }^{(11)}$.

Como podemos notar, a implementação da Política pressupõe a interação entre os Estados e municípios, bem como ministérios e instituições (governamentais e não-governamentais), para a obtenção dos resultados esperados e a consecução dos objetivos da PNAD, como destacam Siqueira, Barbosa, Laranjeira e demonstram Siqueira, Barbosa, Laranjeira, Hopkins no levantamento estadual sobre as instituições capixabas ${ }^{(6-12)}$.

A eficácia no combate aos problemas decorrentes do uso de drogas dependerá da efetiva participação de todos os segmentos da sociedade brasileira. Destaca-se, nesta proposta, o estímulo à ampla participação de grupos organizados da sociedade e o engajamento de instituições, entidades de pesquisa, grupos de auto-ajuda, comunidades terapêuticas e organizações não-governamentais (ONGs), na área da prevenção e tratamento do uso indevido de drogas ${ }^{(13)}$.

Outros recursos disponíveis para o tratamento da dependência química são os grupos de Alcoólicos Anônimos $(A A)$, os quais desempenham um papel fundamental, constituindo-se numa importante estratégia terapêutica para o alcoolismo ${ }^{(14)}$.

Temos também a atuação neste cenário dos conselhos estaduais e municipais anti-drogas que, em consonância com a PNAD e o Sistema Nacional Anti-drogas (SISNAD), são órgãos centrais dos respectivos sistemas, tendo um papel fundamental para garantir a dinamização do esforço realizado por seus elementos integrantes, os conselheiros, dentro da política de municipalização, na causa anti-drogas. Cabe aos conselheiros tornar efetiva as Políticas Estaduais e Municipais Anti-drogas e a cada conselheiro o acompanhamento e a fiscalização do pleno desenvolvimento das ações referentes à redução da demanda de drogas junto aos diversos setores da comunidade ${ }^{(15)}$.

Assim, estudando essa questão desde 2000, o Núcleo de Estudos sobre o Álcool e outras Drogas (NEAD) da Universidade Federal do Espírito Santo (UFES) vem desenvolvendo uma linha de pesquisa sobre políticas públicas relacionadas às substâncias psicoativas que busca analisar a rede de atenção aos usuários de substâncias psicoativas no Estado do Espírito Santo. A área de abrangência desta linha envolve tanto a prevenção como o tratamento; os projetos em desenvolvimento visam atualizar o censo das instituições e o mapeamento da força de trabalho que compõe a rede de atenção. Tais resultados permitirão a análise das políticas públicas vigentes e nortearão pesquisas sobre eficácia e eficiência das ações de prevenção e tratamento, bem como a necessidade de capacitação e formação de recursos humanos para esta área(16-17)

Assim, como membros da equipe técnica do Núcleo de Estudos sobre o Álcool e outras Drogas NEAD (área de Enfermagem) desde 2004, decidimos pela realização do Trabalho de Conclusão do Curso (TCC) de Graduação em Enfermagem com a temática, pois trabalhamos com iniciação científica no projeto intitulado "Atualização das Instituições Especializadas em Dependência Química no ES" que objetivou a atualização censitária das instituições, chamando nossa atenção, em particular, a inexistência de um mapeamento da força de trabalho da enfermagem na área das substâncias psicoativas no Estado do Espírito Santo. Tal situação motivounos para o estudo, de forma a contribuir para com as políticas públicas de alocação de recursos humanos vigentes na área da saúde em nosso Estado através de evidências científicas.

Face ao exposto, o estudo tem como objetivo mapear serviços e equipes de enfermagem de todas as instituições que desenvolvem ações de caráter preventivo e/ou curativo nos 78 municípios do Estado do Espírito Santo.

\section{METODOLOGIA}

Trata-se de um estudo exploratório realizado nos 78 municípios do estado do Espírito Santo, envolvendo todas as instituições, secretarias de saúde, secretarias de ação social e os conselhos estadual e municipal anti-drogas que desenvolvem ações de caráter preventivo e/ou curativo na área de dependência química e que estavam em funcionamento no Estado nos anos de 2004 e 2005. As instituições governamentais compreendem 
aquelas mantidas pelo poder público e as instituições não-governamentais, são as privadas, com ou sem fins-lucrativos. Os grupos de mútua ajuda ( $A A, N A$ e ALANON), não foram visitados, pois os mesmos mantêm um banco de dados atualizado na central do AA, sendo tabulados e analisados separados dos demais.

No ano de 2004 uma parceria realizada entre o Núcleo de Estudos Sobre o Álcool e outras Drogas (NEAD) da Universidade Federal do Espírito Santo (UFES) a Secretaria Estadual de Saúde (SESA), e o Conselho Estadual Antidrogas (COESAD), com financiamento do Ministério Público do Estado do Espírito Santo (MPES), foi iniciado o projeto de pesquisa intitulado "Atualização do Levantamento das Instituições Especializadas em Dependência Química do estado do Espírito Santo" com a finalidade de atualizar o Catálogo das Instituições Especializadas em Dependência Química do Espírito Santo publicado em 2003, envolvendo as organizações governamentais e não-governamentais, atuantes na área de $\operatorname{drogas}^{(15)}$.

Inicialmente foram identificadas no catálogo, as instituições já existentes no Estado para serem visitadas, totalizando 128 , empregando-se a técnica da bola de neve ${ }^{(16)}$. Essa técnica consiste na seleção das novas instituições através das já existentes no primeiro levantamento. Na ocasião, era questionado ao representante, durante a visita, se havia o conhecimento de novas instituições.

A coleta de dados ocorreu em 2004 e 2005, teve como base as Regiões Administrativas de Saúde do Espírito Santo - macro-regiões centro, norte e sul ${ }^{(17)}$ e foi realizada por acadêmicos dos Cursos de Enfermagem e Serviço Social da UFES, sob a orientação de pesquisadores coordenadores. O agendamento da visita foi feito através de um prévio contato telefônico, seguido da entrevista com o representante institucional. A Região Metropolitana (Grande Vitória) composta pelos municípios de Vitória, Serra, Vila Velha, Viana, Cariacica, Guarapari e Fundão foram de responsabilidade dos acadêmicos de Enfermagem e os demais municípios do Estado, ficaram com os acadêmicos de Serviço Social.

$\mathrm{Na}$ tabulação e análise dos dados, foram empregadas, tanto a análise qualitativa (compreensão dos conteúdos), como a quantitativa (estatística descritiva), sendo consideradas as seguintes variáveis: 1 . Distribuição nas macroregiões administrativas de Saúde do ES; 2 . Tipo de Instituição: governamental (OG) e nãogovernamental (ONG); 3. Tipo de assistência prestada; 4. Droga mais consumida e 5. Recursos humanos existentes (equipe de enfermagem).

O projeto de pesquisa foi submetido ao Comitê de Ética em Pesquisa da UFES (CEP 1507/04), sendo estruturado observando-se os dispositivos legais da
Resolução 196/96 do Conselho Nacional de Saúde (CNS). A coleta dos dados foi realizada mediante concordância e assinatura do Termo de Consentimento Livre e Esclarecido e aplicação de um questionário semi-estruturado composto por questões abertas e fechadas, distribuídas em três etapas: I) dados de identificação da instituição, como nome da instituição; nome do dirigente da instituição; endereço; localização (urbano/rural); abrangência; nome do representante legal; registro e documentação necessários ao funcionamento; classificação da instituição; natureza da instituição; regime de atendimento, capacidade de atendimento. II) características das ações realizadas, como tratamento, prevenção, programa dirigido a populações em risco pessoal e social, Grupo de Mútua Ajuda, repressão e III) características do tratamento, se ambulatorial ou internação.

\section{RESULTADOS}

Os resultados serão apresentados considerandose as Macro-regiões Administrativas do Estado do ES ${ }^{(17)}$, através das seguintes análises: distribuição das instituições nas macro-regiões; características das instituições; grupos de ajuda mútua; droga mais consumida, tipo de assistência e a força de trabalho enfermagem.

As três macro-regiões administrativas do Estado foram formadas por aglomerados maiores, com população superior a 500 mil habitantes(18). Cada macro-região, por sua vez, está dividida em microrregiões que, somadas, resumem-se em oito. A Macro-região Norte é formada pelas microrregiões Colatina, São Mateus e Linhares, com um total de 32 municípios. A Macro-região Centro é composta pelas microrregiões Vitória, Serra e Vila Velha, com total de 22 municípios. Por fim, a Macro-região Sul abrange as microrregiões Cachoeiro e Guaçuí que possuem 24 municípios.

A Tabela 1 apresenta a distribuição das instituições de tratamento de usuários de substâncias psicoativas nas macro-regiões administrativas do Espírito Santo, observando-se uma maior concentração destas na macro-região centro $(59,4 \%)$, seguida da norte $(22,7 \%)$ e da sul $(17,9 \%)$. Dados que corroboram com os obtidos por Garcia e Siqueira(19) no I Levantamento Estadual, onde $42.2 \%$ dos recursos situavam-se na região metropolitana da Grande Vitória. 
Tabela 1: Distribuição das instituições de tratamento de usuários de substâncias psicoativas, segundo as macro-regiões administrativas do Espírito Santo, 2006.

\begin{tabular}{ccc}
\hline Macrorregião & Instituições (N) & Porcentagem (\%) \\
\hline Centro & 76 & 59,4 \\
Norte & 29 & 22,7 \\
Sul & 23 & 17,9 \\
\hline TOTAL & $\mathbf{1 2 8}$ & $\mathbf{1 0 0 , 0}$ \\
\hline
\end{tabular}

Todos os municípios do Estado responderam positivamente à existência da demanda, logo estes apresentam problemas com drogas. Porém os que não tinham nenhuma ação desenvolvida para esta problemática referiram encaminhar a demanda para outros municípios que tinham ações, seja em sua macro-região ou não. A concentração de instituições na macro-região centro resulta em uma distribuição desigual dos recursos de saúde no ES, ficando as demandas das macro-regiões norte e sul sem uma assistência efetiva e de qualidade, o que prejudica também a assistência prestada aos usuários da macro-região centro em virtude da demanda proveniente de outras macro-regiões.
Os achados demonstram claramente a necessidade de descentralização de ações, corroborando a proposta da PNAD (2003), em que as mesmas seriam desenvolvidas através da criação dos Conselhos Estadual e Municipais sobre Drogas (COESAD e COMADs, respectivamente), em parceria com a comunidade.

Os dados da Tabela 2 mostram que a maioria das instituições governamentais (OG) e não governamentais (ONG) estão na macro-região centro $(47,8 \%$ e $72,8 \%$, respectivamente), seguida da norte $(30,5 \%$ e $13,6 \%$, respectivamente) e da sul $(21,7 \%$ e $13,6 \%$, respectivamente).

Tabela 2: Características das instituições de tratamento de substâncias psicoativas, segundo as macrorregiões administrativas do Espírito Santo, 2006.

\begin{tabular}{ccc}
\hline Macrorregião & Governamental (OG) & Não-governamental (ONG) \\
\hline Centro & $47,8 \%$ & $72,8 \%$ \\
Norte & $30,5 \%$ & $13,6 \%$ \\
Sul & $21,7 \%$ & $13,6 \%$ \\
\hline TOTAL & $\mathbf{1 0 0 , 0}$ & $\mathbf{1 0 0 , 0}$ \\
\hline
\end{tabular}

O crescimento das organizações religiosas vem preocupando o governo federal, o que resultou em esforço do MS e da SENAD na proposta de acreditação destas unidades. Isso se reflete em investimentos pautados em duas lógicas: (a) o modelo explicativo do fenômeno, em que a dependência química é vista ora como "maldição", ora como "pecado" ou ora como "culpa" e a via de resolução seria a fé. Coloca-se assim, como recurso barato e acessível a uma população cada vez mais excluída do sistema de saúde oficial; (b) a necessidade de o Estado regular as ações e avaliar sua eficácia/eficiência ${ }^{(14)}$.
Os grupos de auto-ajuda são constituídos com a intenção de complementar os tratamentos médicos e psicológicos, incentivando os portadores de doença mental a uma melhor aceitação de sua doença, permitindo mudanças de atitudes frente a ela e contribuindo para uma melhor qualidade de vida. Observa-se na Tabela 3 uma concentração da oferta destes grupos na macro-região Centro $(61,8 \%)$, seguida da Sul $(35.1 \%)$ e da Norte $(19,8 \%)$. E, com relação aos tipos de grupos de ajuda mútua, os AAs são maioria (119) nas três macro-regionais, seguido do NA (24) e do ALANON (10).

Tabela 3: Grupos de ajuda mútua, segundo as macrorregiões administrativas do Espírito Santo, 2006.

\begin{tabular}{cccccc}
\hline Macrorregional & AA & ALANON & NA & TOTAL & $\%$ \\
\hline Centro & 53 & 9 & 19 & $\mathbf{8 1}$ & 61,8 \\
Norte & 24 & 1 & 1 & $\mathbf{2 6}$ & 19,8 \\
Sul & 42 & 0 & 4 & $\mathbf{4 6}$ & 35,1 \\
\hline TOTAL & $\mathbf{1 1 9}$ & $\mathbf{1 0}$ & $\mathbf{2 4}$ & $\mathbf{1 3 1}$ & $\mathbf{1 0 0 , 0}$ \\
\hline
\end{tabular}

Fonte: Central de AA do ES, 2006.

Como mostra a Gráfico 1 , o álcool $(68,4 \%)$, a maconha $(12,6 \%)$ e o crack $(8,4 \%)$ são as drogas mais consumidas pelos usuários internados nessas instituições em nosso Estado. Pode-se notar que o consumo de álcool no ES $(68,4 \%)$ está elevado e que acarreta graves prejuízos à saúde individual e familiar, bem como, impactos para toda a sociedade. 
Gráfico 1: Drogas proporcionalmente mais consumidas segundo as instituições de tratamento de usuários de substâncias psicoativas no Espírito Santo, 2006.

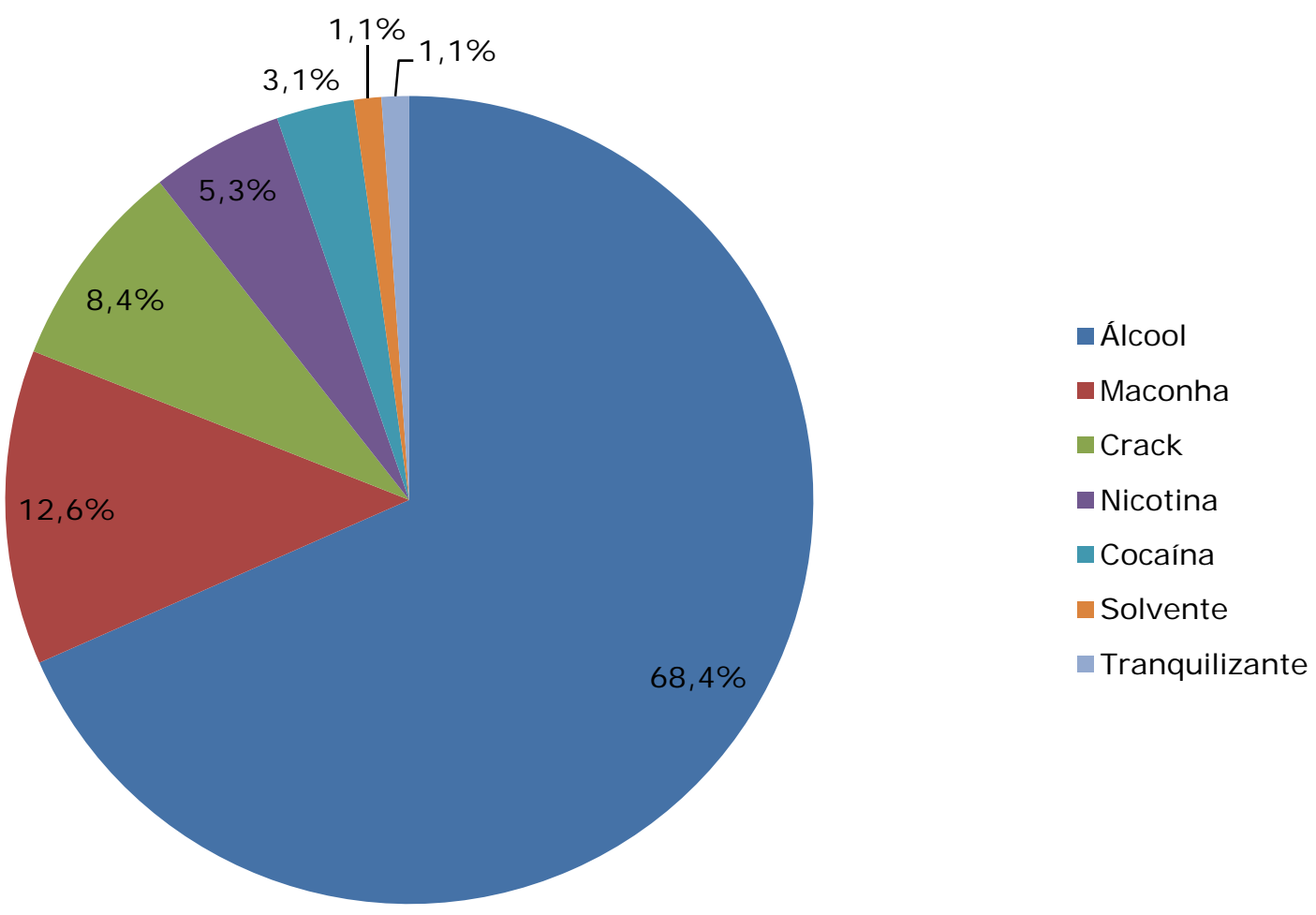

Por fim, deve haver no país, assim como já acontece com o tabaco, uma mudança na legislação para coibir a propaganda de bebidas alcoólicas pela mídia, ficando esta restrita apenas aos locais de vendas. Produtores, distribuidores e estabelecimentos que vendem bebidas devem conscientizar-se que também são responsáveis pelos dados alarmantes das co-morbidades provocadas pelo álcool e assim serem envolvidos nas campanhas de prevenção.

Analisando-se a Gráfico 2, percebe-se que na macrorregião Centro está concentrada a maior oferta de tratamento ambulatorial $(68,5 \%)$, bem como instituições de internação $(61,2 \%)$.

Gráfico 2: Tipo de assistência prestada pelas instituições de tratamento de usuários de substâncias psicoativas no Espírito Santo, 2006.

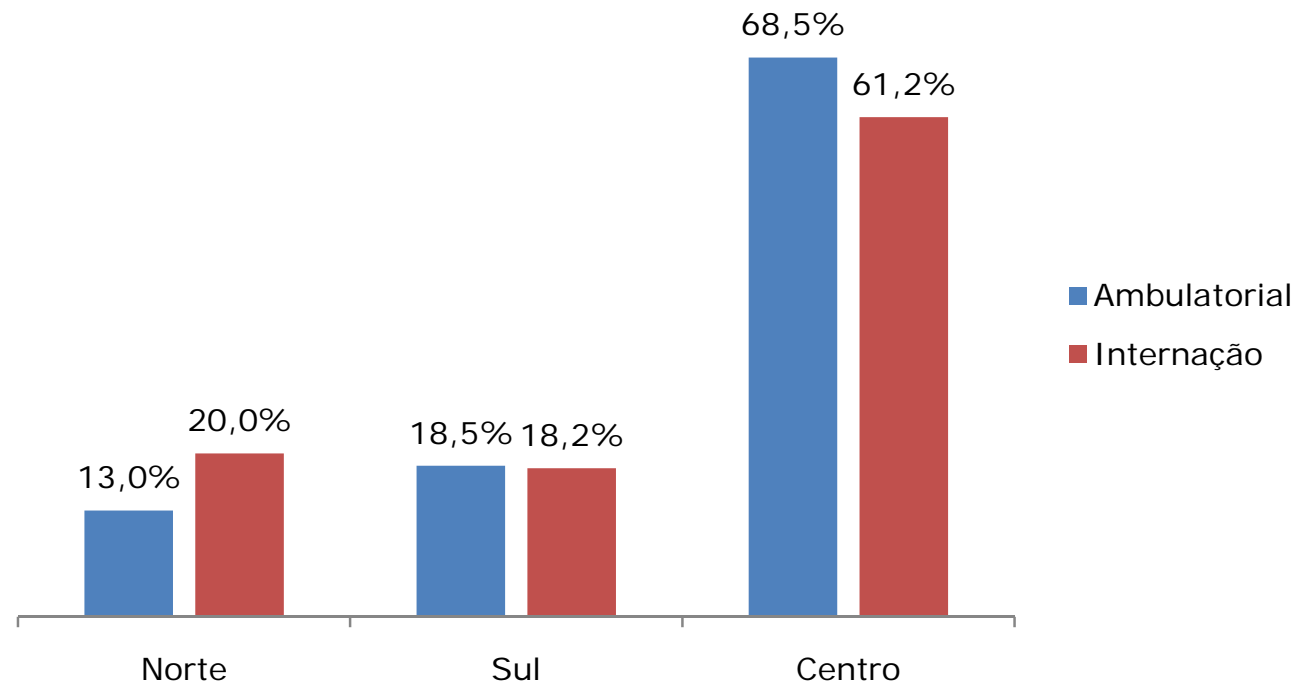


As macro-regiões Norte e Sul juntas representam cerca de $31,5 \%$ da assistência ambulatorial. Devido a essa carência, os municípios encaminham sua demanda para a macro-região Centro, prioritariamente, para o Centro de Prevenção e Tratamento ao Toxicômano (CPTT), na capital do Estado. Esse fato mostra que, de acordo com a lógica da descentralização preconizada pelo SUS, o Espírito Santo vem, progressivamente, adotando esse sistema intermediário. Entretanto, a macro-região Centro é a única que possui serviço substitutivo ao hospital psiquiátrico do tipo CAPsad/NAPS, fazendose necessária uma ampliação dos mesmos nas demais macro-regiões.

No âmbito federal tem-se o Programa de Atendimento ao Alcoolista (PAA) do Hospital Universitário Cassiano Antônio Moraes (HUCAM) da UFES, situado em Vitória. Este é um programa de extensão, de caráter interdisciplinar e ambulatorial, criado em 1985 como resposta às demandas identificadas na instituição de um número significativo de pacientes atendidos nos diferentes setores do hospital que apresentavam problemáticas relacionadas a um padrão de consumo abusivo de etanol, com enorme repercussão orgânica, psíquica e social ${ }^{(19)}$.

A macro-região Centro é composta de 22 municípios, concentrando 76 instituições de tratamento de usuários de substâncias psicoativas, sendo 21 delas, situadas no município de Vila Velha e 14, no município da Serra. Esses municípios juntos totalizam 46\% das instituições dessa macro-região.

Apesar da evidencia de maior número de instituições que prestam assistência em caráter de internação na macro-região Centro, o maior número de leitos psiquiátricos disponibilizados pelo SUS se concentra na macro-região Sul, com destaque para a Clínica Psiquiátrica Santa Isabel, que dispõe de 400 leitos e desses, $98 \%$ são destinados a pacientes oriundos do SUS, através de convênio com o Governo do Estado.

É também importante destacar a presença do Hospital Colônia "Adauto Botelho" que desde sua criação, na década de 50, foi a maior e mais importante instituição de internação psiquiátrica, com uma capacidade de 300 leitos na década de 90. Esse hospital possui um serviço ambulatorial para atender exclusivamente aos dependentes químicos, criado em 2001, que se inseriu na nova lógica da Política Estadual Anti-drogas.

No Gráfico 3 é apresentada a distribuição da equipe de enfermagem nas instituições governamentais e não-governamentais existentes no Estado. A macro-região Centro possui um maior número de instituições com equipe de enfermagem, tanto nas governamentais, quanto nas nãogovernamentais, uma vez que nesta região situam-se
$59,4 \%$ do total das instituições especializadas no tratamento de usuários do Estado. Além disso, percebe-se que na macro-região Centro 78,9\% das instituições não-governamentais não possuem equipe de enfermagem, resultando num déficit desse profissional e em uma assistência de baixa qualidade. 
Gráfico 3: Distribuição da equipe de enfermagem nas instituições governamentais e não-governamentais do Espírito Santo, 2006.

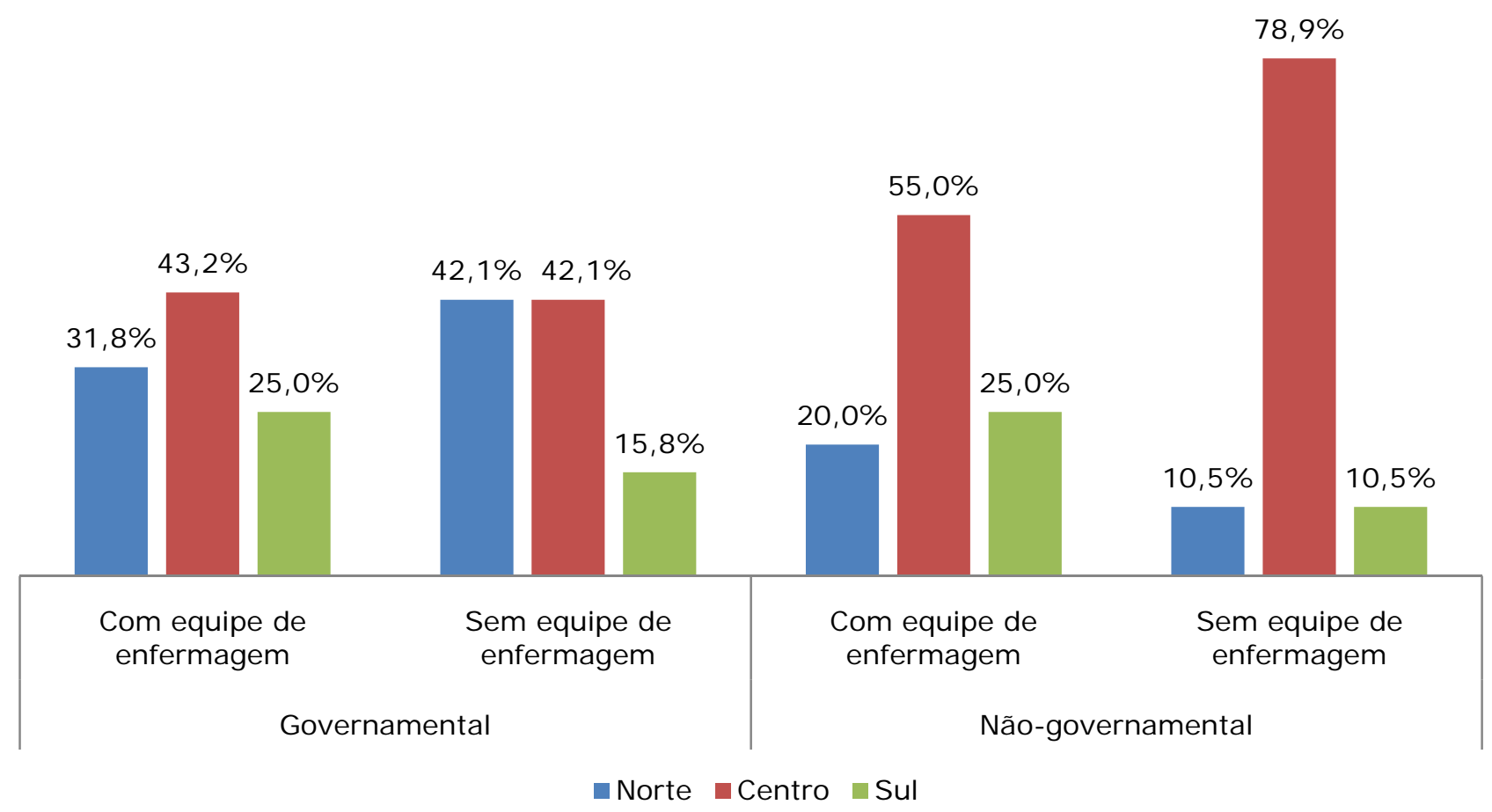

Somado a isto, outro aspecto que merece nossa atenção é o fenômeno nacional de crescimento progressivo das comunidades terapêuticas, que baseiam seu tratamento na fé, muitas vezes considerando-a o suficiente para a recuperação do usuário. Assim, o tratamento dispensa a utilização de técnicos, substituídos por conselheiros espirituais, deixando em segundo plano a assistência de equipes de saúde qualificada para este tipo de cuidado, dentre elas a enfermagem. No I Levantamento Estadual das Instituições Especializadas em Dependência Química no ES foi observado que $49,1 \%$ das organizações não-governamentais são mantidas por grupos religiosos no Espírito Santo ${ }^{(15)}$.

\section{CONCLUSÕES}

O consumo de substâncias psicoativas é algo que preocupa a sociedade capixaba e brasileira, visto que é um grave problema de saúde pública.

A maior concentração de instituições para o tratamento de usuários de substâncias psicoativas no Estado situa-se na macro-região Centro, gerando deslocamentos, sobrecarga dos serviços existentes e aumento dos gastos com o tratamento. Assim, a pequena abrangência das ações nas demais regiões, implica em deficiência de articulação dos recursos entre os serviços de um mesmo município ou outro, bem como, entre as diversas regiões.

A não-descentralização dos recursos compromete a qualidade da assistência prestada, bem como, a implantação de projetos de prevenção e redução de demanda. E, a inexistência de capacitação e treinamento dos profissionais da atenção básica na área de dependência química vai de encontro à atual meta de saúde mental do Governo do Estado.

A atenção aos indivíduos na esfera da saúde ainda encontra-se centrada na lógica hospitalocêntrica, principalmente nas regiões Centro (metropolitana) e Sul. Existe uma concentração dos recursos do SUS no hospital psiquiátrico, em detrimento dos serviços ambulatoriais de base comunitária, estando estes em maior concentração na macro-região Centro, conforme discutido anteriormente.

Essa escassez de assistência nas macro-regiões Norte e Sul dificulta a identificação de dados epidemiológicos que são importantes para o planejamento da política estadual de saúde mental.

Observa-se uma deficiência de recursos humanos especializados no tratamento dos usuários de substâncias psicoativas, principalmente de enfermeiros, dificultando o diagnóstico e a qualidade da assistência prestada, o que pode influenciar no prolongamento do tempo de uso destas substâncias, ocasionando danos irreversíveis à saúde física e mental, não só dos usuários, mas, também, de seus familiares.

Em virtude da falta de mão-de-obra, faz-se necessário repensar a formação acadêmica, pois se 
observa pouco interesse durante a graduação e, posteriormente, do profissional no mercado de trabalho, mesmo atuando na área. Assim, o desenvolvimento de capacitação de recursos humanos na área de saúde mental é necessário para que haja uma diretriz clara, bem como, uma mudança efetiva nas ações, a fim de melhorar o atendimento à clientela.

\section{REFERÊNCI AS}

1. Schneider DR, Spohr B, Accorsi M, Leitão C, Scatamburlo N. Avaliação crítica dos serviços de atenção à dependência química da Região da Grande Florianópolis: Projeto de Pesquisa-Funpesquisa. In: Anais da 3ạ SEPEX; 2003 jun 4-7; Florianópolis, Brasil. p. 100.

2. Organização Mundial da Saúde. Classificação de transtornos mentais e de comportamento - CID 10. Descrições clínicas e diretrizes diagnósticas. Caetano D, translator. Porto Alegre: Artes Médicas; 1993.

3. Leite MC. Aspectos básicos do tratamento da síndrome de dependência de substâncias psicoativas. 2nd ed. Brasília: SENAD; 2001.

4. Carter B, Mcgoldrick M. As mudanças no ciclo de vida familiar: uma estrutura para terapia familiar. Porto Alegre: Artes Médicas; 1995.

5. Ministério da Saúde; Secretaria Nacional Antidrogas. Política Nacional Antidrogas. Brasília (Brasil): Ministério da Saúde; 2001.

6. Siqueira MM, Barbosa DA, Laranjeira R. As políticas públicas relacionadas às substâncias psicoativas e o papel do Estado. Revista Enfermagem Atual. 2008; (45): 25-9.

7. Presidência da República. Constituição da República Federativa do Brasil. Brasília (Brasil): Senado Federal; 1988.

8. Ministério da Saúde; Reforma Psiquiátrica e Política de Saúde Mental no Brasil: Conferência regional de reforma de saúde mental, 15 anos depois de Caracas. Brasília (Brasil): Ministério da Saúde; 2005.

9. Alves DSN, Seidl EL, Schechtman A, Silva RC. Reestruturação da atenção em saúde mental: situação atual, diretrizes e estratégias. In: Amarante P (org). Psiquiatria Social e Reforma Psiquiátrica. Rio de Janeiro: FIOCRUZ; 1994.p.195-202.

10. Ministério da Saúde; Secretaria Executiva; Coordenação Nacional de DST e AIDS. A Política do Ministério da Saúde para Atenção Integral a Usuários de Álcool e outras Drogas. Brasília (Brasil): Ministério da Saúde; 2003.

11. Ministério da Saúde; Secretaria Nacional Antidrogas. Seminário Internacional de Políticas Públicas sobre Drogas. Brasília (Brasil): Ministério da Saúde; 2004.

12. Siqueira MM, Barbosa DA, Laranjeira R, Hopkins

K. Psychoactive Substances and the Provision of
Specialized Care: The Case of Espírito Santo. Rev. Bras. Psiquiatr. 2007;29(4):315-23.

13. Pereira ET. Política Nacional Antidrogas: subsídios a sua constituição e construção [dissertation]. Espírito Santo: Programa de Pós-Graduação em Saúde Coletiva/UFES; 2002. 222 p.

14. Campos EA. As representações sobre o alcoolismo em uma associação de ex-bebedores: os alcoólicos anônimos. Cad. Saúde Pública. 2004; 20(5): 1379-87.

15. Ministério da Saúde; Secretaria Nacional Antidrogas. Homogeneização de conhecimentos para conselheiros estaduais antidrogas compartilhando procedimentos e práticas comuns. Brasília (Brasil): Ministério da Saúde; 2002.

16. Coleman J. Relational Analysis: the study of social organization with silvery methods. Human Organization. 1958; 17:28-36.

17. Secretaria Estadual de Saúde. Plano Regional de Desenvolvimento. Vitória: SESA; 2003.

18. Ferreira LEA. Análise de Política Pública de Saúde Mental: o caso do Estado do Espírito Santo/ES [dissertation]. Rio de Janeiro: Universidade Federal do Rio de Janeir; 2005.

19. Garcia MLT, Siqueira MM. Catálogo das instituições especializadas em dependência química no Estado do Espírito Santo. Vitória: UFES; 2003.

Artigo recebido em 25.11.07.

Aprovado para publicação em 25.05.09. 